\title{
Fire Examination of Superhigh-Rise Apartment Building "Wooshin Golden Suites" in Busan, Korea
}

\author{
Young-sun $\mathrm{Kim}^{1}$, Masayuki Mizuno ${ }^{1}$ and Yoshifumi Ohmiya ${ }^{2}$ \\ ${ }^{1}$ Center for Fire Science \& Technology, Research Institute for Science \& Technology, \\ Tokyo University of Science, Japan \\ ${ }^{2}$ Department of Architecture, Tokyo University of Science, Japan
}

\section{INTRODUCTION}

With rapid advance of construction technology, buildings have become much larger and higher. East Asian cities also have a forest of superhigh-rise buildings backed by their economic development. With many buildings, cities changed their skylines and superhigh-rise buildings with characteristic appearance are now regarded as the landmark of the city.

As superhigh-rise buildings are built by fully integrating state-of-the-art construction technology, construction of superhigh-rise buildings and formation of cities having those tall buildings represent the technological or economic strength of the nation. In fact many people believe they are the symbol of the nation.

To give some examples of superhigh-rise building fires in recent years, there are cases including destruction of World Trade Center by terrorism in New York, USA in 2001, Windsor building fire in Madrid, Spain in 2005 and CCTV high-rise building fire in Beijing, China in 2009 among others. As seen in these examples, fires in superhighrise buildings often burnt down and entirely destroyed the building, and yet the overcrowding trend of cities seems to continue.

Under such circumstances, South Korea entered the rush to build superhigh-rise residential buildings in 1990s mainly in Seoul starting with the construction of 30-story residential building in early 1990s. Eventually in 2000s, buildings principally designed for residential use including superhigh-rise residential and commercial complexes or officetels (buildings with units that can be used as either office or house) became higher than 70 stories.

South Korea shows different tendency from other advanced nations in situations that led to build superhigh-rise buildings. The reasons are described as follows.[1]

Firstly, although high-/superhigh-strength and high performance concrete is used as structural component of buildings in order to bear the vertical load, studies and accumulation of technology concerning its performance have yet been insufficient. The rush to build residential and commercial complexes by leading constructors started before they learned enough knowledge and thus they are said to be too early to expand business. Secondly, because they have not reached social consensus on disaster prevention system such as appropriate disaster prevention equipment or laws and technical guidelines of interior/exterior materials, they have been just carrying out 
heuristic measures. Thirdly, development of legal system to control those heuristic measures is promoted so rapidly that even experts in concerned field cannot catch up with it.

In a situation that more and more superhigh-rise buildings are built one after another, a fire broke out in a 140-meter high and 38-story building ("Wooshin Golden Suites") located in Marine City, the center area of Haeundae, Busan in South Korea in the morning of October 1, 2010. The fire rapidly spread to upper levels and burnt wide range of outside wall and inside of some floors. Although there was no loss of human live or serious damage to building structure, we found that combustible exterior material had certain influence at the time of fire. Therefore Tokyo University of Science Global COE Program conducted a field survey. This article presents the conditions of "Wooshin Golden Suites" fire and explores problems in superhigh-rise building fire.

\section{OVERVIEW OF "WOOSHIN GOLDEN SUITES”}

\subsection{Location}

"Wooshin Golden Suites" is a 38-story officetel building located in Marine City, about $1 \mathrm{~km}$ away from famous and celebrated Haeundae beach as shown in Figure 1.

Marine City was planned to be a high end residential district and as you can see in Image 1, over 100-meter high buildings stand close together along with luxurious resort facilities and hotels. Image 2 shows the external appearance of "Wooshin Golden Suites" before it was damaged in fire. As its name represents, outside wall was colored gold. It can be assumed that the building is composed of two areas connected by a hallway in the floor plan.

\subsection{Building Structure}

- Location : Haeundae district, Busan, South Korea

- Constructor: Wooshin Construction

- Completion: December 2005

- Floors : 38 stories above and 4 stories under ground

- Structure : SRC structure (S structure and RC structure in part)

- Height: Approximately 140 meters

- Floor Area: (Total) 68,917 $\mathrm{m}^{2}$

- Floor Area : (Standard Floor) 1,935m²

The first floor of the building is a commercial area, and on second and third floor are shared facilities including an exercise gym, a pool and meeting rooms for users. The fourth floor is filled with equipment and called PIT level, and 5th through 38th floors are office rooms. However most of the rooms on 5th to 38th floors are officetels equipped with floor heating and used as residential units rather than offices. 


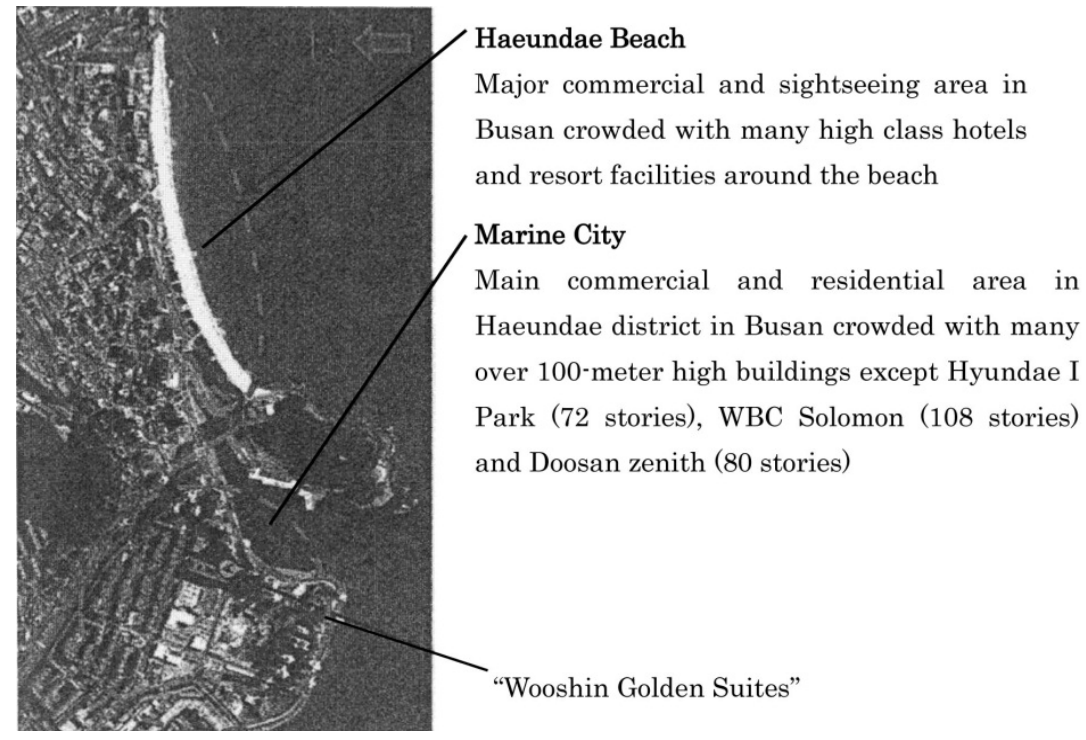

Figure 1 Location of "Wooshin Golden Suites" in Busan city [2]

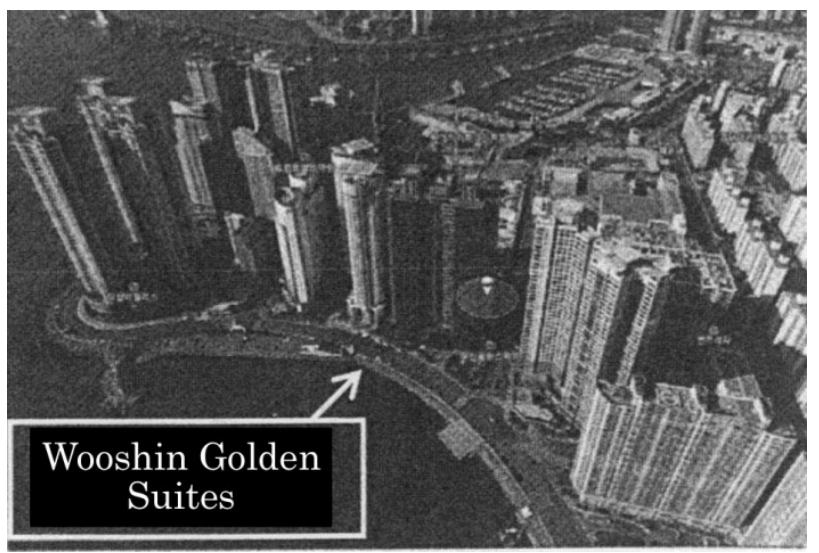

Image 1 “Wooshin Golden Suites” and around 


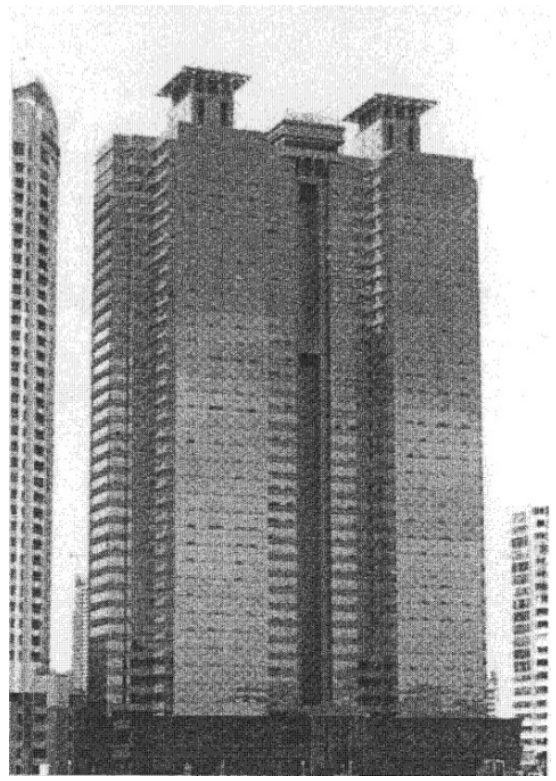

Image 2 External appearance of "Wooshin Golden Suites" before damaged in fire

\section{OVERVIEW OFTHE FIRE}

The fire broke out from the PIT level on the fourth floor which divided commercial area on lower levels and offices and residential units on upper levels. The cause of the fire is reported to be a spark generated around a socket near the door of men's dressing room for administrators of the building and the spark seemed to ignite nearby objects. Then as shown in Figure 2, the fire rapidly expanded rushing up along the outside wall and burnt the sky lounge and the penthouse on the top floor and some residential units on the 37th floor. Image 3 presents the damaged building which faced to the coast taken from the back side at the time of the fire. The smoke generated on the coast side of the building rose from the upper levels as well as hang around lower levels on the opposite side of the beach. Image 4 is the external appearance of the building after damaged by the fire. The image shows the finishing material of outside wall was burnt upward. The course of the fire announced by the South Korea fire department is briefly summarized in Table 1. Total floor area inside the building that was burnt down in the fire reached $1,134 \mathrm{~m}^{2}$. In addition, exterior finishing material from 4th through 38th floors was also destroyed by the fire. Human damage was small as only four people slightly injured but financial damage amounted to more than 400 million yen. 


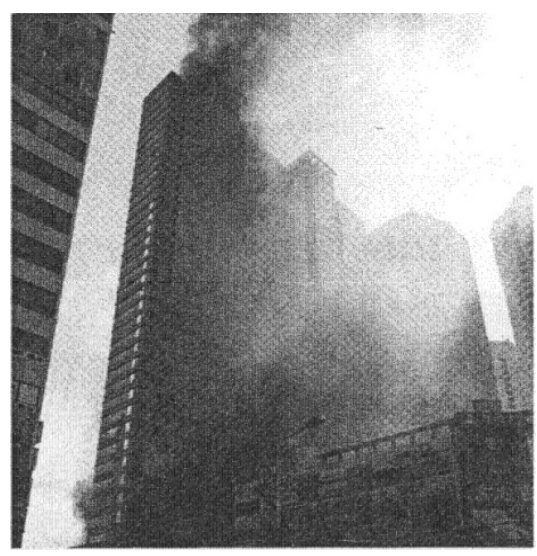

Image 3 The fire scene of "Wooshin Golden Suites" [3]

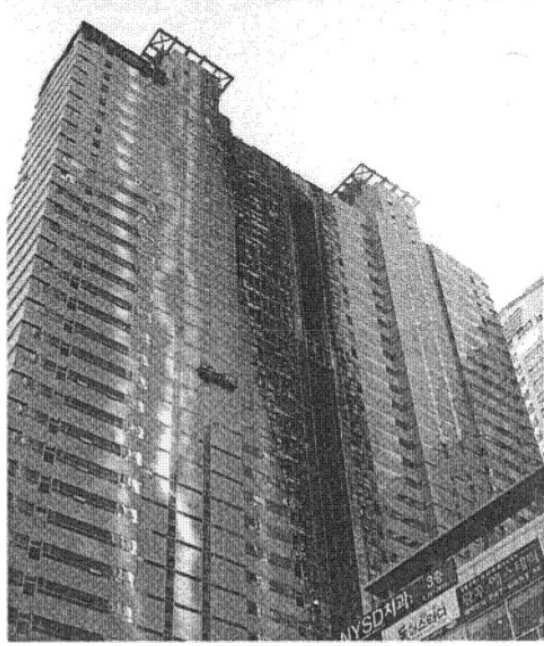

Image 4 External appearance of "Wooshin Golden Suites" after damaged in fire

Table 1 The course of the fire

\begin{tabular}{|l|l|}
\hline 11:21 a.m. & Fire broke out (according to neighbors ) \\
\hline 11:33 a.m. & Report to the fire station \\
\hline 11:36 a.m. & The first firefighting team arrived at the scene \\
\hline 11:44 a.m. & Evacuation guidance and rescue efforts by firefighters began \\
\hline 12:10 p.m. & Rescued 10 people using snorkel (ladder truck) \\
\hline 13:00 p.m. & 9 people who had escaped onto the roof were rescued by helicopter \\
\hline 13:02 p.m. & Extinguished fire around the fire origin floor \\
\hline 18:48 p.m. & Fire of entire building was put out \\
\hline
\end{tabular}




\section{SPREAD OFTHE FIRE ONTHE OUTSIDE WALL}

In this chapter, we will summarize the conditions of the fire based on the information obtained from the fire department officials who supported our field survey and on our assumptions.

As stated above, the fire broke out from a spark of socket around 11:21 a.m. on October 1, 2010. Then the fire spread from inside of the building to outside wall as shown in Figure 2.

Only in 20 minutes, the fire spread to the roof and burnt down the sky lounge, the penthouse and some units on 37th floor.

Flammable wall panel

Fanned by strong wind blowing upward, the fire rapidly expanded through ventilation pipes in central stairways and along outside wall.

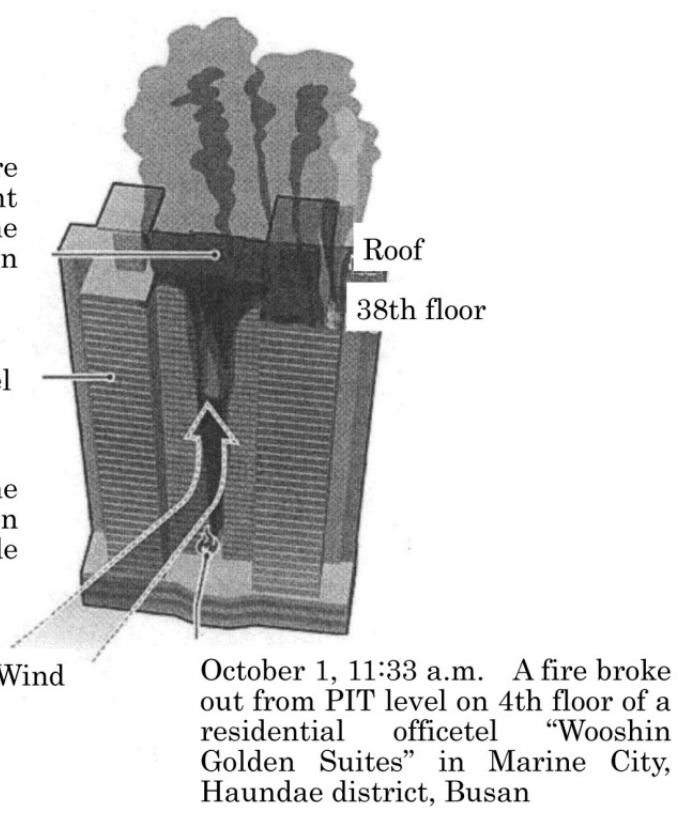

Figure 2 Description of the "Wooshin Golden Suites" fire [3]

The outside wall was made of aluminum composite panel and its core material was composed of polyethylene. As outside of the panel was exposed to hot current (including flame) ejected from an opening, the surface temperature rose and aluminum dissolved. In addition, combustible gas derived by thermal decomposition of the core material caught the fire and burnt the outside wall. Then the high-temperature gas rose along the wall to further accelerate dissolution of aluminum and combustion of polyethylene core material, and the damage spread upward. It is considered that the sequence of dissolution and combustion of the panel resulted in rapid and wider expansion of the fire upward along the wall. Accordingly, it only took about 20 minutes for the fire to burn from the fire source floor (4th floor) through 38th floor after the fire broke out. This indicates the spread of the fire was extremely rapid by burning the outside wall.

We can also point out that strong wind blowing from the sea and the surface shape of the wall created the complicated conditions and affected fire expansion. To be specific, the part of the outside wall where the fire spread was in the form of hollow. Therefore 
when strong wind from the sea hit the hollow-shaped wall, the wind flew up along the wall and possibly fostered expansion of the fire. In addition, in a similar way as the ordinal surface or corners of wall, temperature decrease of thermal current moving upward along the U-shaped hollow is slower than in free space, and high temperature part tends to spread upward. Furthermore, walls facing to each other or being at right angle each other are prone to mutually transfer radiant heat. These conditions also seemed to encourage the fire to burn surface of the wall and expand upward.

\section{MAJOR PROBLEMS INTHE FIRE}

"Wooshin Golden Suites" fire revealed that superhigh-rise buildings in South Korea have poor resistance to fire. In the following sections, we will sort out major problems.

\subsection{Flammability of Outside Wall}

In South Korea, there is no regulation on the use of combustible external material. The biggest problems in "Wooshin Golden Suites" fire was that outside wall using combustible material burnt intensely and the fire rapidly spread upward due to the surface shape and strong wind at the time.

Exterior finishing material used in the outside wall is called aluminum composite panel with small load and high usability in construction, which is especially effective to decrease structural load and reduce construction cost of superhigh-rise buildings. As Figure 3 explains, aluminum composite panel is connected to angles and then fixed to concrete wall.

Figure 4 shows the pattern of aluminum composite panel. On the core material made of combustible polyethylene resin, aluminum sheet, some kinds of coating material and protection film are piled up to ensure beautiful surface appearance as well as strength and resistance. Coating material and aluminum sheets are very thin and not fireresistant as the melting point of aluminum is at about $660^{\circ} \mathrm{C}$. Also, considering that they have high thermal conduction rate and polyethylene ignite at 350 to $400^{\circ} \mathrm{C}$, it is very likely that they easily ignite and burn when exposed to heat expected in case of fire.

If incombustible material had been used in the outside wall, such a significant spread of fire could have been prevented. After "Wooshin Golden Suites" fire, the importance of fire-resistant capability of wall is recognized again in South Korea. On the contrary, since more than $80 \%$ of high-rise buildings in South Korea were built using combustible material, immediate response to this situation is strictly required. 


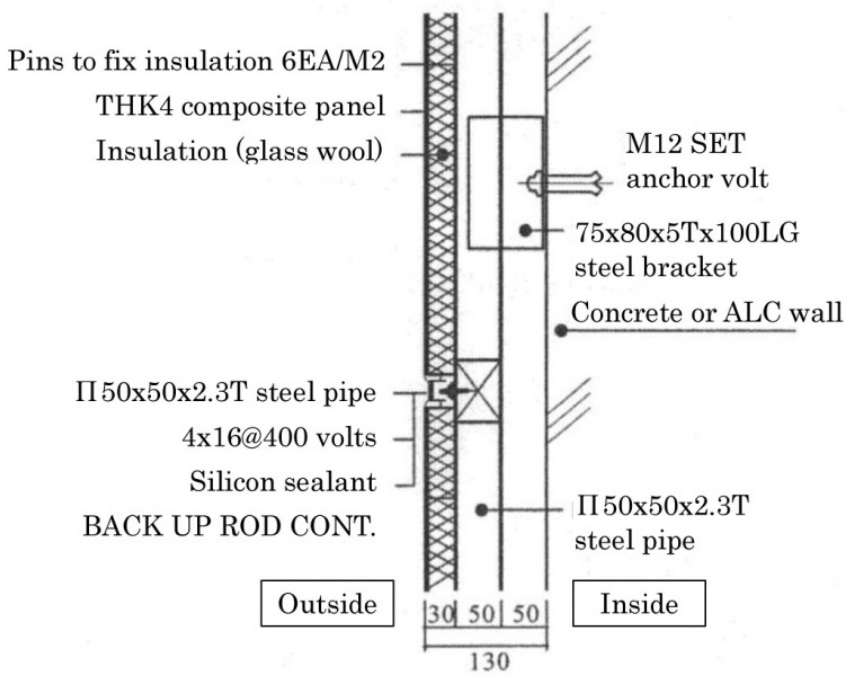

Figure 3 Cross section of the outside wall structure

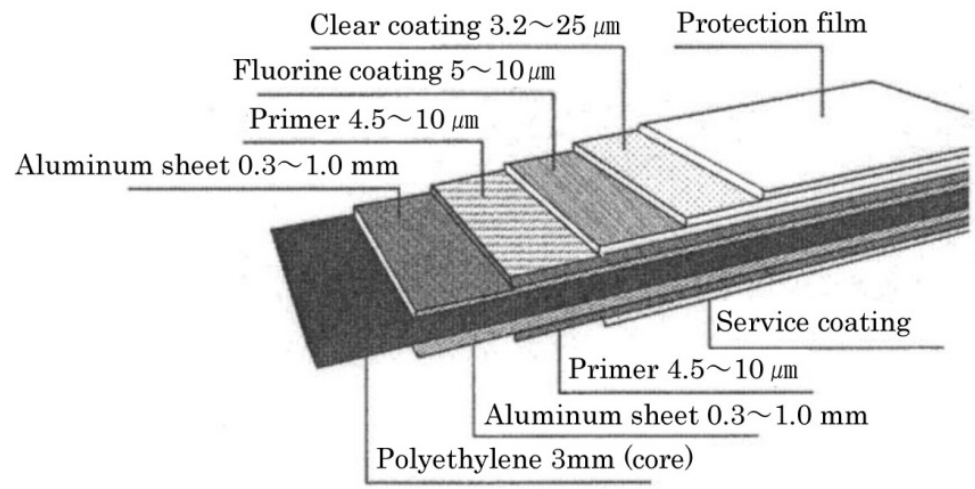

Figure 4 Pattern of aluminum composite panel (the top faces to outside)

\subsection{Difficulty in Evacuation and Rescue Activity}

The second problem is that lower than 50-story buildings in South Korea are not subject to regulations requiring mid-level emergency evacuation space and other measures because they are classified as high-rise but not superhigh-rise buildings. Therefore, high-rise buildings having 16th to 40th levels where snorkels (pump truck with folding ladder) cannot reach are not covered by these regulations. Fortunately "Wooshin Golden Suites" fire did not take human lives, but some people in the building escaped onto the roof and were rescued by helicopter. As the buildings become higher, vertical distance to escape become longer and people have to pay larger physical cost. Therefore, considering the features of superhigh-rise buildings, installation of mid-level 
evacuation space and immediate introduction of evacuation measures such as installing elevators exclusively for evacuation even in lower than 50-story high-rise buildings are strongly required.

\subsection{Problems in Space Maintenance and Control}

The third problem is that PIT level being planned exclusively to be an equipment floor was used illegally as garbage collection and separation space. PIT levels are usually placed between floors above ground and basement floors or between the top floor and the roof to house water supply and drainage system and electric equipment. In residential and commercial complexes, PIT levels sometimes serve as equipment floor that divide residential levels from commercial levels. Like washrooms, PIT levels are not required to install automatic fire-extinguishing equipment such as sprinkler system. This seems to be based on the assumption that the risk of fire breaking out and spreading on PIT levels is very low mainly because they have only small amount of combustible material. However, by bringing in combustible objects and using for daily needs, the risk of fire naturally increase. Decision of what fire resistance measures should be installed in certain space depends on the supposed purpose of the space on the design plan, but when the space is used for another purpose beyond planned expectations, it become difficult to control the risk of fire. Therefore, we can point out the importance of strict control and maintenance of the building.

\section{CONCLUSION}

At the beginning of this article, we mentioned that superhigh-rise buildings represent cutting-edge construction technology of the day. However they still have been actually damaged or possible to be damaged in fire. It is necessary to improve safety of buildings in accordance with economic and financial limitations and requirements. By examining "Wooshin Golden Suites" fire, we pointed out the risk of fire expansion caused by the use of aluminum composite panel made of combustible material which is generally used in outside wall in South Korea because of its low cost, usability in construction and less structural load. Also, in addition to already well-known problem of vertical evacuation (people going up or down to escape), we pointed out a problem of inappropriate use of space beyond the expected purpose. There are a lot of superhigh-rise buildings and they are still increasing in South Korea. While formation of the world's leading cities with many superhigh-rise buildings is expected, there is strong need to avoid bringing significant damage in fire. Therefore, we consider South Korea should seriously face to the problems revealed in "Wooshin Golden Suites" fire as well as improve technical development and enhance necessary regulations. Also we would like to suggest those involved including design and construction companies, building administrators and users should recognize the risk of fire in superhigh-rise buildings and reconsider measures to secure safety. 


\section{ACKNOWLEDGEMENT}

The field survey for this report was conducted with the support from the Global COE Program granted by the Ministry of Education, Culture, Sports, Science and Technology (Tokyo University of Science "Center for Education and Research on Advanced Fire Safety Science and Technology in East Asia"). Here we express our gratitude for its contribution.

\section{REFERENCES}

1. Kwon, young-jin, The Limit Performance of Concrete as a Fire Proof Materials and Fire Performance of Super Tall Residential Building, Magazine of the Korea Concrete Institute, Vol. 17, No. 5, 8-13, 2005

2. http://maps.google.com

3. Busan Fire Department (http://119.busan.go.kr, accessed on February 1, 2011) 